\title{
Jeno Manninger, Ulrich Bosch, Peter Cserhati, Karoly Fekete, György Kazar (eds): Internal fixation of femoral neck fractures-an atlas
}

\author{
Springer, Wien, New York, 2007, XIX 310 pp, 242 illus, Text English, €134.95, ISBN-13: \\ 978-3-211-68583-9 (Hardcover)
}

\section{Pierre Kehr}

Received: 16 August 2009/Accepted: 18 August 2009/Published online: 29 August 2009

(C) Springer-Verlag 2009

The fractures of the proximal end of the femur constitute major public health problems, whose frequency does not cease growing in the developed countries because of the ageing of the population. The team of Professor J. Manninger of Budapest developed a system of osteosynthesis for screwing of the femoral neck. The work is mainly dedicated to him and thus does not constitute an exhaustive and contradictory work on the treatment of the fractures of the neck of the femur. It consists of 12 chapters:

1. Proximal femur fractures: definition, epidemiology, anatomy, biomechanics

2. Pathology off femoral neck fractures

3. Diagnosis and investigation

4. Historical retrospective

5. Biomechanical aspects off cannulated screw fixing
6. Justification for early surgery

7. Reduction off the fracture

8. Internal fixing

9. Femoral Treatment off undisplaced and atypical neck fractures

10. Postoperative treatment, early complications

11. Results off treatment

12. Appendix

Osteosyntheses by triple screwing are well-known with well-indexed indications, and this system of osteosynthesis is not different. Recommended for the curious surgeons having a daily practice about traumatology.

No funds were received in support of this study.

Laurent Balabaud

P. Kehr ( ()

ArgoSpine, Strasbourg, France

e-mail: kehrpier@aol.com 